\title{
Triglycine (GGG) Adopts a Polyproline II (pPII) Conformation in its Hydrated Crystal Form: Revealing the Role of Water in Peptide Crystallization
}

\author{
Mingxia Guo ${ }^{\dagger}$, Ian Rosbottom ${ }^{\dagger}$, Lina Zhou ${ }^{\S}$, Chin W. Yong", Ling Zhou ${ }^{\S}$, Qiuxiang Yin ${ }^{\S}$, Ilian T. \\ Todorov ${ }^{\|}$Ethan Errington ${ }^{\dagger}$ and Jerry Y.Y. Heng ${ }^{\dagger *}$ \\ Department of Chemical Engineering, Institute for Molecular Science and Engineering, Imperial College London, South \\ Kensington Campus, London SW7 2AZ, UK \\ §School of Chemical Engineering and Technology, State Key Laboratory of Chemical Engineering, Tianjin University, \\ Tianjin 300072, P. R. China \\ "Scientific Computing Department, UKRI Science and Technology Facilities Council, Daresbury Laboratory, Warrington, \\ WA4 4AD, UK
}

\begin{abstract}
Polyproline II (pPII) is a left-handed 3 -helix conformation, which has been observed to be the most abundant secondary structure in unfolded peptides and proteins compared to $\alpha$-helix and $\beta$-sheet. Although pPII has been reported as the most stable conformation for several unfolded short chain peptides in aqueous solution, it is rarely observed in their solidstate. Here, we show for the first time a glycine homopeptide (gly-gly-gly) adopting the pPII conformation in its crystalline dihydrate structure. The single crystal X-ray structure with molecular dynamic simulation calculations suggests that a network of water and the charged carboxylate group is critical in stabilising the pPII conformation in solid state, offering an insight into the structures of unfolded regions of proteins and the role of water in peptide crystallization.
\end{abstract}




\section{Table of Contents}

This information supports the main manuscript and contains:

S1: Crystallisation process of Mono- (alpha form), di- (alpha) and tri- (beta) glycine from aqueous solution at variable supersaturations and cooling rates

S2: The thermal and spectroscopic characterization of triglycine anhydrate and dihydrate

S3: The single crystal cultured and solved process

S4: The hydrogen bond propensity calculation of anhydrous forms of glycine, diglycine and triglycine, as well as the new TGDH form.

S5: The crystallographic information of TGDH

S6: Molecular modelling process

S7: Visualization of the Ramachandran space

S8: Radial density functions of triglycine terminal groups and water

S9: Visualization of water structuring in solution via radial density functions

S10: The conformation (dihedral angle) and packing coefficient of glycine, diglycine, triglycine and TGDH 
S1: Crystallisation process of Mono- (alpha form), di- (alpha) and tri- (beta) glycine from aqueous solution at variable supersaturations and cooling rates

Mono- (alpha form), di- (alpha) and tri- (beta) glycine (molecular structures shown in Scheme 1) were purchased from Sigma Aldrich (all $>99 \%$ purity) and crystallised from aqueous solution at variable supersaturations and cooling rates.

$5 \mathrm{~mL}$ triglycine solutions with different supersaturation levels $(\mathrm{S}=1.4,1.6,1.8,1.9,2.0,2.1,2.2$ and 2.3$)$ were prepared in $10 \mathrm{~mL}$ crystallisers at $333.15 \mathrm{~K}$ and then cooled down to $283.15 \mathrm{~K}$ at different cooling rate $(0.1 \mathrm{~K} / \mathrm{min}$, $0.3 \mathrm{~K} / \mathrm{min}, 0.5 \mathrm{~K} / \mathrm{min}, 1 \mathrm{~K} / \mathrm{min}, 2 \mathrm{~K} / \mathrm{min}$ ). The solutions were stirred at $500 \mathrm{rpm}$ during the cooling process. TGDH was collected after filtration at room temperature. Suspension crystallisation was also launched to confirm dihydrate was the most stable form in water when the temperature was lower than $283.15 \mathrm{~K}$.

\section{S2: The thermal and spectroscopic characterization of triglycine anhydrate and dihydrate} In order to identify the solid form and structure of TGDH, the powder products of triglycine and TGDH were characterised by Optical microscopy, Scanning electron microscopy (SEM), Powder X-ray Diffraction (PXRD), Thermogravimetric analysis (TGA), Differential scanning calorimetry (DSC), Fourier transform infrared spectroscopy (FTIR) and Raman microscope.

\section{SEM}

Scanning Electron Microscopy (SEM) pictures of Triglycine and TGDH were taken by a JEOL-JSM-6700F scanning electron microscope. The samples were coated with a thin layer of gold. Figure $1 \mathrm{~b}$ shows that the triglycine is plate shape, however the dihydrate looks like thin rod, and very easily to aggregate together.

\section{PXRD}

Powder XRD patterns were obtained on a PANalytical X' Pert PRO X-ray diffractometer at $40 \mathrm{kV}$ and $40 \mathrm{~mA}$ with $\mathrm{Cu} K \alpha$ radiation $(\lambda=1.5406 \AA)$. The samples were conducted over a 2 -theta range from $2^{\circ}$ to $50^{\circ}$ at a scanning rate of 1 step/s. The XRD pattern (Figure 1c) of the rodlike crystal has several new diffraction peaks (at $2 \theta=9.03$, $9.93,12.24$ and 21.93 degree), which suggests a new polymorph for triglycine.

TGA

The water loss of TGDH was determined by thermogravimetric analysis using a TGA Q500 (TA Instruments, New Castle, DE, USA). The TGA measurements were performed from $298.15 \mathrm{~K}$ to $850 \mathrm{~K}$ at a heating rate of $10 \mathrm{~K} / \mathrm{min}$. A constant nitrogen flow of $60 \mathrm{~mL} / \mathrm{min}$ was used to prevent thermal oxidation processes. Sample weight was approximately $6 \mathrm{mg}$. The weight loss of TGDH at $353.68 \mathrm{~K}$ was $15.99 \%$, corresponding to two water molecules loss in TGDH (Figure S1). 


\section{DSC}

DSC of Triglycine and TGDH were measured with a Discovery DSC Q2000 (TA Instruments, New Castle, DE, USA) from $298.15 \mathrm{~K}$ to $850 \mathrm{~K}$ at a scan rate of $10 \mathrm{~K} \cdot \mathrm{min}^{-1}$. The measurements were carried out using $5.00 \pm 0.10$ $\mathrm{mg}$ samples under a helium atmosphere $\left(50 \mathrm{~mL} \cdot \mathrm{min}^{-1}\right)$. From DSC pattern, there is a new endothermic peak before $400 \mathrm{~K}$ in TGDH, which corresponds to heat absorption from water loss in the crystal structure (Figure S1).
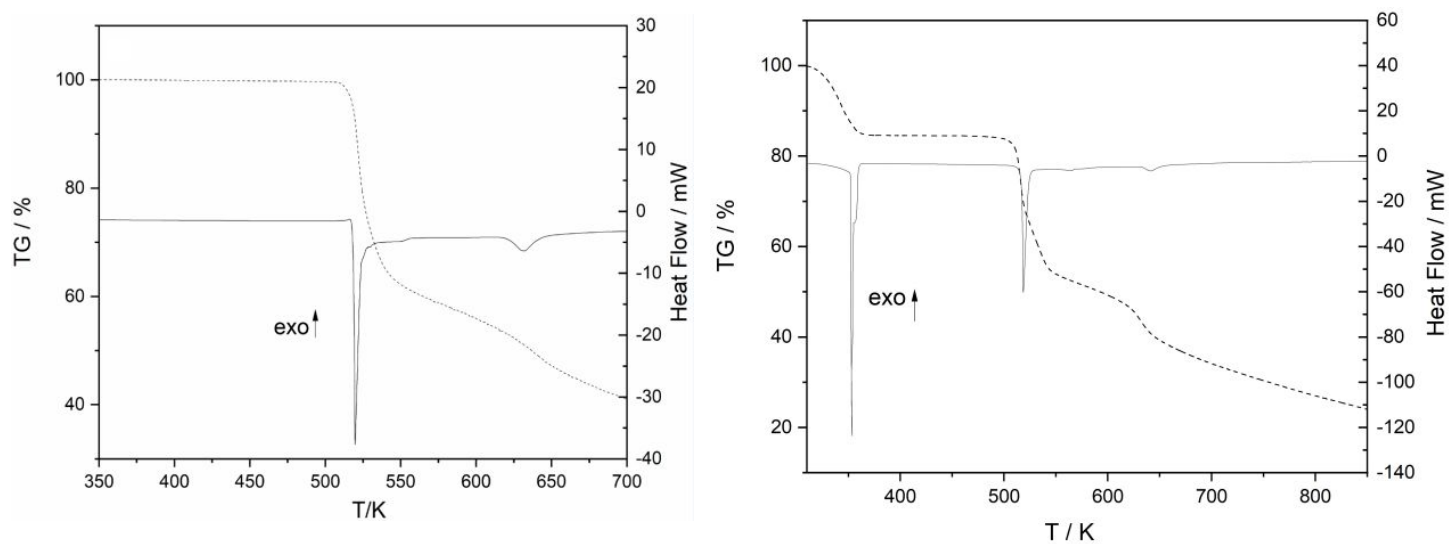

Figure S1. The DSC and TGA images of Triglycine (left) and TGDH (right)

\section{FTIR \& RAMAN}

The interaction of water molecule and triglycine molecule can be verified using the FT-IR and Raman spectroscopy, which were shown in Figure S2. FT-IR spectroscopy was recorded on Cary 630 FT-IR spectrometer. The range of the wavenumber was 4000-650 $\mathrm{cm}^{-1}$ with resolution $2 \mathrm{~cm}^{-1}$. Raman spectra was obtained using the Raman microscope Bruker Senterrall. The integration time was $4 \mathrm{~s}$ with 1 co-addition for each measurement spot. The power of the laser was $12.5 \mathrm{~mW}$ with a wavelength of $532 \mathrm{~nm}$.
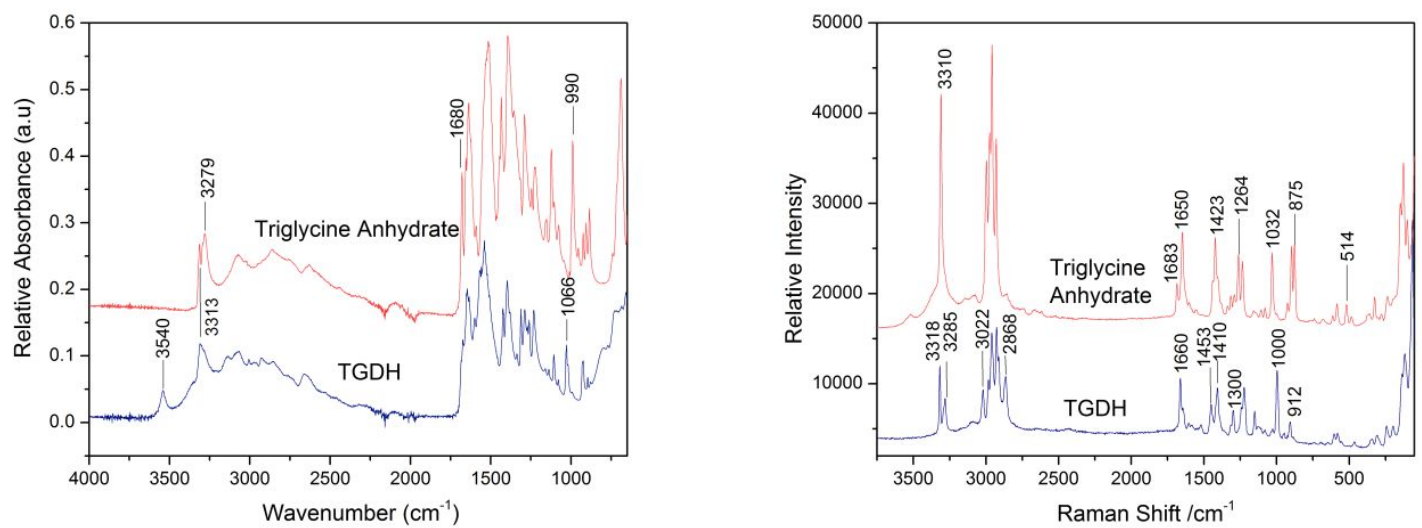

Figure S2. The FT-IR(Left) and Raman (Right) spectrograms of Triglycine anhydrate and TGDH 

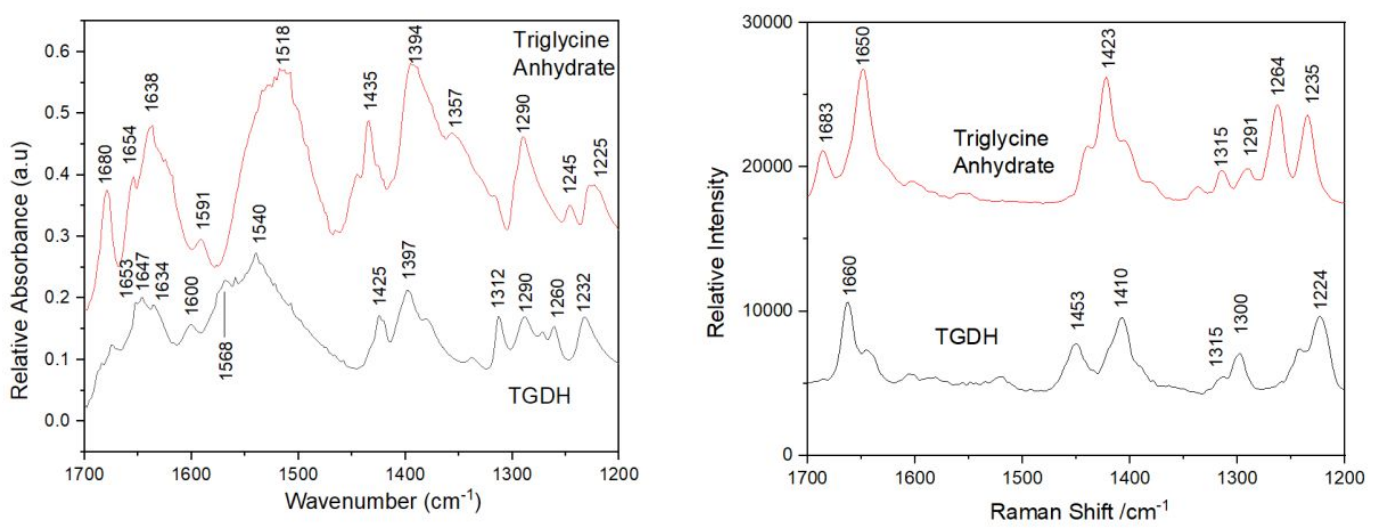

Figure S3 The amide modes in FT-IR(Left) and Raman (Right) spectrograms of Triglycine anhydrate and TGDH

As shown in FT-IR spectra, the broad band of O-H stretching vibration at frequency $2500-3300 \mathrm{~cm}^{-1}$ can be seen in both anhydrate and dihydrate, which are caused by the interaction between $\mathrm{COO}^{-}$and $\mathrm{NH}^{3+}$ groups of adjacent triglycine molecules. However, there is a new peak at $3540 \mathrm{~cm}^{-1}$ corresponds to the hydrogen-bonded O-H group, which comes from the two water molecules in TGDH crystal structure. Besides, the bands for anhydrate at $3313 \mathrm{~cm}^{-1}$ and $3279 \mathrm{~cm}^{-1}$ in FT-IR, corresponding to the stretching vibration of $\mathrm{N}-\mathrm{H}$ bond and $\mathrm{N}-\mathrm{H}_{2}$ bond, merge to one wider band in TGDH, which indicates the existence of hydrogen bond between $\mathrm{N}-\mathrm{H}$ and water. This change also leads to the band at $990 \mathrm{~cm}^{-1}$ attributed to C-N stretch vibration has a slight shift to $1066 \mathrm{~cm}^{-1}$. The new hydrogen bonding between $\mathrm{N}-\mathrm{H}$ and water can also been verified from significant change of bands at $3310 \mathrm{~cm}^{-1}$ and $2850-3000 \mathrm{~cm}^{-1}$ which contributed to bonded symmetric $\mathrm{N}-\mathrm{H}_{2}$ stretching and bonded $\mathrm{C}-\mathrm{H}$ stretching, respectively in Raman spectra.

Furthermore, it can be seen in figure $S 3$ that the amide I band shifts from $1680 \mathrm{~cm}^{-1}$ for $\beta$-sheet in anhydrate to around $1660 \mathrm{~cm}^{-1}$ for pPII in dihydrate in both FT-IR and Raman. The amide II band upshifts from $1518 \mathrm{~cm}^{-1}$ for $\beta$ sheet to $1540 \mathrm{~cm}^{-1}$ and $1568 \mathrm{~cm}^{-1}$ for PPII in FT-IR. The peaks in amide III band (around $1300 \mathrm{~cm}^{-1}$ ) upshift to the higher wavenumbers which correspond the transformation from $\beta$-sheet to pPII conformation. Besides, some vibration changes of other groups can be seen from Raman: the bands at $1423 \mathrm{~cm}^{-1}, 1264 \mathrm{~cm}^{-1}, 1032 \mathrm{~cm}^{-1}$ and $875 \mathrm{~cm}^{-1}$ corresponding to stretching vibration of $\mathrm{C}-\mathrm{H}_{2}, \mathrm{C}-\mathrm{H}, \mathrm{C}-\mathrm{C}$ and $\mathrm{C}-\mathrm{O}$, respectively, all slightly shift because of the new conformation of the dihydrate.

\section{S3: The single crystal growth and solve process}

Triglycine aqueous solutions were prepared in different concentrations $(20 \mathrm{mg} / \mathrm{mL}, 25 \mathrm{mg} / \mathrm{mL}, 30 \mathrm{mg} / \mathrm{mL}$, $35 \mathrm{mg} / \mathrm{mL}, 40 \mathrm{mg} / \mathrm{mL}, 45 \mathrm{mg} / \mathrm{mL}, 50 \mathrm{mg} / \mathrm{mL})$ at room temperature and filtered with filter membranes $(0.22 \mu \mathrm{m})$, then the clear liquid were moved into 35 small sealed glass vessels with different hole numbers $(1,2,3,4,5)$ on the caps and keep them at $278.15 \mathrm{~K}$. The single crystal of TGDH was cultured by allowing the solvent to slowly evaporate from the aqueous solution of triglycine at $278.15 \mathrm{~K}$. After two weeks, the single crystal appeared in the $50 \mathrm{mg} / \mathrm{mL}$ solution and the other single crystals appeared in the following days in the $45 \mathrm{mg} / \mathrm{mL}$ and $40 \mathrm{mg} / \mathrm{mL}$ solutions. The crystals found in the bulk solution during solvent evaporation were all identified as the TGDH form.

The SCXRD data was collected on an Rigaku Saturn 70 abstract diffractometer with a MoK $\backslash$ a radiation source $(\lambda=$ $0.71073 \AA$ A). The single crystals with suitable sizes were placed on a fiber needle on the goniometer of the X-ray diffractometer and then purged with a cooled nitrogen gas stream at $113.15 \mathrm{~K}$ throughout the data collection. Using Olex $2^{1}$, the structure was solved with the ShelXT ${ }^{2}$ structure solution program using Intrinsic Phasing and refined with the SheIXL refinement package ${ }^{2}$ using Least Squares minimisation. The crystal data was already sent to CCDC with a deposition Number 2049957. 


\section{SUPPORTING INFORMATION}

\section{S4: The hydrogen bond propensity calculation of anhydrous forms of glycine, diglycine and triglycine, as well as the new TGDH form.}

The hydrogen bond propensity calculations reveal how well coordinated hydrogen bonding groups of a molecule are, as compared to similar functional groups in different molecules in the Cambridge Structural Database, where under coordinated hydrogen-bonding interactions can indicate a metastable crystalline form. ${ }^{3}$<smiles>CC(C)COC(=O)C(C)C</smiles><smiles>CC(C(=O)O)C(=O)C(C)C(C)C</smiles>

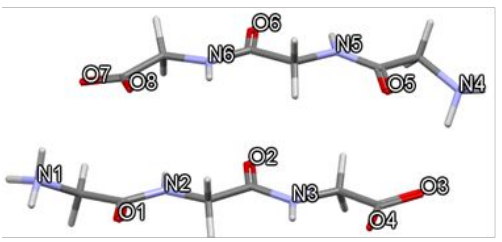<smiles>CC(C)C(C)NC(=O)C(C)C(C)C(C)(C)C(C)(C)C</smiles>

\section{Alpha glycine}

\begin{tabular}{|c|c|c|c|c|c|c|c|}
\hline Atom (D/A) & $=0$ & $=1$ & $=2$ & $=3$ & $=4$ & $=5$ & $>=6$ \\
\hline N1 of acyclic_T4C_nh3 (d) & 0.000222169 & 0.00228635 & 0.00181489 & 0.425452 & 0.384529 & 0.142083 & 0.0436126 \\
\hline 01 of carboxylate (a) & 0.0147985 & 0.274169 & 0.611357 & 0.0859672 & 0.0137088 & 0 & 0 \\
\hline 02 of carboxylate (a) & 0.0116566 & 0.199474 & 0.661438 & 0.112368 & 0.0150633 & 0 & 0 \\
\hline
\end{tabular}

Alpha di-glycine

\begin{tabular}{|l||l||l|l||l|l||l|l|}
\hline Atom (D/A) & $=0$ & $=1$ & $=2$ & $=3$ & $=4$ & $=5$ & $>=6$ \\
\hline \hline N1 of acyclic_T4C_nh3 (d) & 0.000225077 & 0.00163915 & 0.00389396 & 0.473299 & $\mathbf{0 . 3 7 1 2 7 4}$ & 0.109792 & 0.0398768 \\
\hline \hline N2 of acyclic_amide (d) & 0.0529412 & $\mathbf{0 . 9 2 9 9 3 9}$ & 0.0171199 & 0 & 0 & 0 & 0 \\
\hline \hline O1 of acyclic_amide (a) & 0.105109 & $\mathbf{0 . 8 3 2 1 7 9}$ & 0.0598389 & 0.00287246 & 0 & 0 & 0 \\
\hline \hline O2 of carboxylate (a) & 0.0154385 & 0.282182 & $\mathbf{0 . 6 0 9 3 7 8}$ & 0.0828543 & 0.0101465 & 0 & 0 \\
\hline \hline O3 of carboxylate (a) & 0.0127447 & 0.222374 & $\mathbf{0 . 6 5 4 1 4 7}$ & 0.100458 & 0.0102755 & 0 & 0 \\
\hline
\end{tabular}

\section{Triglycine}

\begin{tabular}{|l||l|l|l|l||l|l|l|}
\hline Atom (D/A) & $=0$ & $=1$ & $=2$ & $=3$ & $=4$ & $=5$ & $>=6$ \\
\hline \hline N1 of acyclic_T4C_nh3 (d) & 0.000183852 & 0.000912672 & 0.00467055 & $\mathbf{0 . 4 9 4 9 4 7}$ & 0.355698 & 0.0979732 & 0.045615 \\
\hline \hline N2 of acyclic_amide (d) & 0.0328259 & $\mathbf{0 . 9 5 0 1 2 9}$ & 0.017045 & 0 & 0 & 0 & 0 \\
\hline \hline N3 of acyclic_amide (d) & 0.0721432 & $\mathbf{0 . 9 1 3 6 8 8}$ & 0.0141691 & 0 & 0 & 0 & 0 \\
\hline \hline N4 of acyclic_T4C_nh3 (d) & 0.000272025 & 0.00109748 & 0.00602817 & 0.511659 & $\mathbf{0 . 3 5 3 4 2 1}$ & 0.0882684 & 0.0392533 \\
\hline \hline N5 of acyclic_amide (d) & 0.0577438 & $\mathbf{0 . 9 2 6 7 7 8}$ & 0.0154779 & 0 & 0 & 0 & 0 \\
\hline \hline N6 of acyclic_amide (d) & 0.0456387 & $\mathbf{0 . 9 3 9 0 2}$ & 0.0153408 & 0 & 0 & 0 & 0 \\
\hline \hline O1 of acyclic_amide (a) & 0.0952948 & $\mathbf{0 . 8 2 0 6 0 5}$ & 0.0808868 & 0.00321296 & 0 & 0 & 0 \\
\hline \hline O2 of acyclic_amide (a) & 0.0834248 & $\mathbf{0 . 8 2 1 3 2 5}$ & 0.091268 & 0.00398208 & 0 & 0 & 0 \\
\hline \hline O3 of carboxylate (a) & 0.0124426 & 0.208087 & 0.654468 & $\mathbf{0 . 1 1 3 4 1 8}$ & 0.0115836 & 0 & 0 \\
\hline \hline O4 of carboxylate (a) & 0.0160801 & 0.326274 & $\mathbf{0 . 5 8 5 1 7 8}$ & 0.0671825 & 0.00528572 & 0 & 0 \\
\hline \hline O5 of acyclic_amide (a) & $\mathbf{0 . 1 0 3 4 6 7}$ & 0.821071 & 0.0727918 & 0.00267051 & 0 & 0 & 0 \\
\hline \hline O6 of acyclic_amide (a) & 0.0920262 & $\mathbf{0 . 8 2 4 0 2}$ & 0.0807502 & 0.0032034 & 0 & 0 & 0 \\
\hline \hline O7 of carboxylate (a) & 0.0119408 & 0.194273 & $\mathbf{0 . 6 6 0 5 6 4}$ & 0.120764 & 0.0124582 & 0 & 0 \\
\hline \hline O8 of carboxylate (a) & 0.0158519 & $\mathbf{0 . 3 1 9 8 4}$ & 0.590108 & 0.0687775 & 0.00542244 & 0 & 0 \\
\hline
\end{tabular}

\section{TGDH}

\begin{tabular}{|l|l|l|l|l||l||l|l|}
\hline Atom (D/A) & $=0$ & $=1$ & $=2$ & $=3$ & $=4$ & $=5$ & $>=6$ \\
\hline \hline N1 of acyclic_amide (d) & 0.0119678 & $\mathbf{0 . 9 6 8 1 1 8}$ & 0.0199146 & 0 & 0 & 0 & 0 \\
\hline \hline N2 of acyclic_amide (d) & 0.0148798 & $\mathbf{0 . 9 6 6 1 0 4}$ & 0.019016 & 0 & 0 & 0 & 0 \\
\hline \hline N3 of acyclic_T4C_nh3 (d) & 0.000810314 & 0.000810314 & 0.008936 & $\mathbf{0 . 5 1 6 2 1 6}$ & 0.348496 & 0.08907 & 0.0356615 \\
\hline \hline O5 of water (d) & 0.0176761 & 0.0798905 & $\mathbf{0 . 7 7 8 1 3 3}$ & 0.110896 & 0.0134036 & 0 & 0 \\
\hline \hline O6 of water (d) & 0.0176761 & 0.0798905 & 0.778133 & $\mathbf{0 . 1 1 0 8 9 6}$ & 0.0134036 & 0 & 0 \\
\hline \hline O1 of carboxylate (a) & 0.00421729 & 0.0933393 & $\mathbf{0 . 6 3 7 0 1 3}$ & 0.234137 & 0.0312937 & 0 & 0 \\
\hline \hline O2 of carboxylate (a) & 0.0073327 & 0.245075 & 0.627765 & $\mathbf{0 . 1 0 7 8 8 9}$ & 0.0119386 & 0 & 0 \\
\hline \hline O3 of acyclic_amide (a) & 0.0539267 & $\mathbf{0 . 7 9 8 6 3 4}$ & 0.144538 & 0.00290162 & 0 & 0 & 0 \\
\hline \hline O4 of acyclic_amide (a) & 0.0746331 & $\mathbf{0 . 8 2 5 8 9 1}$ & 0.0980415 & 0.00143443 & 0 & 0 & 0 \\
\hline \hline O5 of water (a) & 0.102736 & 0.625291 & $\mathbf{0 . 2 5 0 0 5 8}$ & 0.0138867 & 0.00802926 & 0 & 0 \\
\hline \hline O6 of water (a) & 0.102736 & $\mathbf{0 . 6 2 5 2 9 1}$ & 0.250058 & 0.0138867 & 0.00802926 & 0 & 0 \\
\hline
\end{tabular}

Figure S4. Left are the molecular structures and labelled $\mathrm{H}$-bonding groups for alpha glycine, alpha diglycine, beta triglycine and TGDH. Right are the $\mathrm{H}$-bonding propensities tables, which show the coordination of $\mathrm{H}$-bonds to these groups from other crystal structures in the CSD, with the number bolded corresponding to the coordination found in these glycine homopeptides crystal structure. If the label is green it indicates that the coordination found in the crystal structure corresponds with the majority of other structures found in the database, if it is red then this coordination is more unusual. 


\section{S5: The crystallographic information of TGDH}

Table S1. The crystallographic data of TGDH

\begin{tabular}{|c|c|}
\hline Parameters & Triglycine Dihydrate (TGDH) \\
\hline Formula & $\mathrm{C}_{6} \mathrm{H}_{11} \mathrm{~N}_{3} \mathrm{O}_{4} \cdot 2\left(\mathrm{H}_{2} \mathrm{O}\right)$ \\
\hline Formula weight (g/mol) & 225.21 \\
\hline Temperature (K) & 113.15 \\
\hline Crystal system, space group & Orthorhombic, Pca21 \\
\hline a $(\AA ̊)$ & $21.5256(8)$ \\
\hline$b(\AA)$ & $9.7968(4)$ \\
\hline$c(\AA)$ & $4.7685(2)$ \\
\hline$\alpha\left(^{\circ}\right)$ & 90 \\
\hline$\beta\left({ }^{\circ}\right)$ & 90 \\
\hline$\gamma\left({ }^{\circ}\right)$ & 90 \\
\hline$V\left(\AA^{3}\right)$ & $1005.59(7)$ \\
\hline Z & 4 \\
\hline Density (calculated) $\left(\mathrm{mg} / \mathrm{m}^{3}\right)$ & 1.488 \\
\hline$F(000)$ & 480 \\
\hline Crystal colour / morphology & Colourless needles \\
\hline Crystal size $\left(\mathrm{mm}^{3}\right)$ & $0.38 \times 0.10 \times 0.08$ \\
\hline$\mu / \mathrm{mm}^{-1}$ & 0.132 \\
\hline Radiation & $\operatorname{MoK} \alpha(\lambda=0.71073)$ \\
\hline $2 \Theta$ range for data collection $\left({ }^{\circ}\right)$ & 3.784 to 57.394 \\
\hline Index ranges & $-29 \leq h \leq 29,-13 \leq k \leq 13,-6 \leq \mathrm{I} \leq 6$ \\
\hline Reflections collected & 12303 \\
\hline Independent reflections & $2602[$ Rint $=0.0521$, Rsigma $=0.0335]$ \\
\hline Data/restraints/parameters & $2602 / 1 / 172$ \\
\hline Goodness-of-fit on F2 & 1.041 \\
\hline Final $R$ indexes $[I>=2 \sigma(I)]$ & $\mathrm{R} 1=0.0466, \mathrm{wR} 2=0.1277$ \\
\hline Final $R$ indexes [all data] & $R 1=0.0492, w R 2=0.1305$ \\
\hline Largest diff. peak/hole / e $\AA^{-3}$ & $0.43 /-0.29$ \\
\hline Flack parameter & $0.5(6)$ \\
\hline
\end{tabular}


Table S2. Bond Lengths for TGDH

\begin{tabular}{cccccc}
\hline Atom & Atom & Length $(\AA)$ & Atom & Atom & Length $(\AA ̊)$ \\
\hline O1 & C1 & $1.256(3)$ & N2 & C4 & $1.457(3)$ \\
O2 & C1 & $1.262(3)$ & N2 & C5 & $1.335(3)$ \\
O3 & C3 & $1.232(3)$ & N3 & C6 & $1.482(3)$ \\
O4 & C5 & $1.239(3)$ & C1 & C2 & $1.538(4)$ \\
N1 & C2 & $1.452(3)$ & C3 & C4 & $1.524(3)$ \\
N1 & C3 & $1.343(3)$ & C5 & C6 & $1.517(3)$ \\
\hline
\end{tabular}

Table S3. Bond Angles for TGDH

\begin{tabular}{cccccccc}
\hline Atom & Atom & Atom & Angle $(\AA)$ & Atom & Atom & Atom & Angle( $\AA$ ) \\
\hline C3 & N1 & C2 & $119.2(2)$ & O3 & C3 & C4 & $120.9(2)$ \\
C5 & N2 & C4 & $120.8(2)$ & N1 & C3 & C4 & $116.4(2)$ \\
O1 & C1 & O2 & $124.8(2)$ & N2 & C4 & C3 & $110.7(2)$ \\
O1 & C1 & C2 & $116.3(2)$ & O4 & C5 & N2 & $123.9(2)$ \\
O2 & C1 & C2 & $118.9(2)$ & O4 & C5 & C6 & $120.6(2)$ \\
N1 & C2 & C1 & $113.42(19)$ & N2 & C5 & C6 & $115.4(2)$ \\
O3 & C3 & N1 & $122.7(2)$ & N3 & C6 & C5 & $109.86(19)$ \\
\hline
\end{tabular}

Table S4. Torsion Angles for TGDH

\begin{tabular}{cccccccccc}
\hline A & B & C & D & Angle $(\AA)$ & A & B & C & D & Angle( $(\AA)$ \\
\hline O1 & C1 & C2 & N1 & $159.1(2)$ & C2 & N1 & C3 & O3 & $3.1(3)$ \\
O2 & C1 & C2 & N1 & $-21.1(3)$ & C2 & N1 & C3 & C4 & $-176.54(19)$ \\
O3 & C3 & C4 & N2 & $41.9(3)$ & C3 & N1 & C2 & C1 & $-62.6(3)$ \\
O4 & C5 & C6 & N3 & $-3.0(3)$ & C4 & N2 & C5 & O4 & $7.0(4)$ \\
N1 & C3 & C4 & N2 & $-138.4(2)$ & C4 & N2 & C5 & C6 & $-173.3(2)$ \\
N2 & C5 & C6 & N3 & $177.3(2)$ & C5 & N2 & C4 & C3 & $79.9(3)$ \\
\hline
\end{tabular}
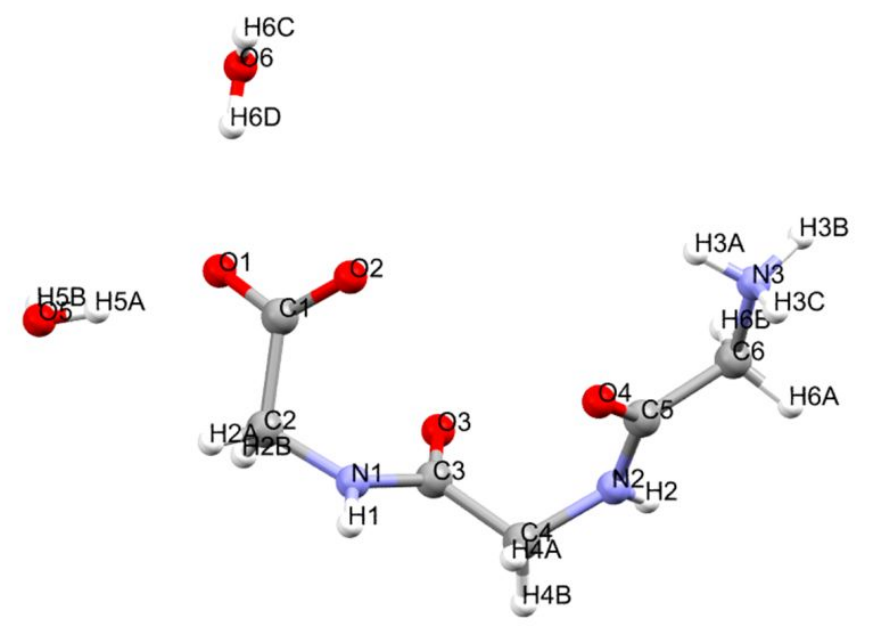

Figure S5. The asymmetric unit in the crystal structure of TGDH. 


\section{S6: Molecular Modelling of Triglycine}

The molecular dynamics simulations were carried out using the DL_POLY $4^{2,4}$, where DL_FIELD ${ }^{5}$ was used to create

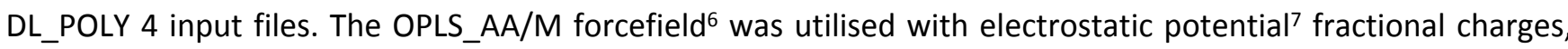
which were calculated at the density functional theory (B3LYP/6-31G*) level ${ }^{8}$, and the TIP3_P water model ${ }^{9}$ was also utilised. A single molecule of triglycine, extracted from the anhydrous crystal structure, was placed in the centre of a $64 \AA \AA \times 64 \AA$ X $64 \AA$ simulation box, which was then filled with water molecules.

The simulations were gently heated to $278 \mathrm{~K}$ using an NVE ensemble and $12 \AA$ cut-off radius for computation of interactions, whereby if the temperature remained constant without any scaling, it was considered equilibrated. The NPT ensemble, using the Nose-Hoover thermostat and barostat ${ }^{10,11}$, with relaxation times of 4 and 5 ps respectively, was applied and the simulation ran for 10 ns with a timestep of 0.002 picoseconds. Further analysis, such as creating trajectory files that omitted the water molecules to extract conformations, utilised DL_ANALYSER ${ }^{12}$. Further details on the development of these methods can be found in the following publication ${ }^{13}$.

\section{S7: Visualization of the Ramachandran space}

To visualise the probability of observing conformers in the Ramachandran space, phi and psi angles of the central alpha carbon in triglycine were taken from simulation trajectories in $2 \mathrm{~ns}$ samples. The symmetry in phi and psi angles which arises from the chirality of triglycine, effectively doubling the dataset size from 580,000 to $1,160,000$. A 2D histogram was then created in the phi, psi space with a total of 250,000 bins - corresponding to 500 bins in each dimension.

\section{S8: Radial density functions of triglycine terminal groups and water}

Radial density functions have been provided as an alternate means of understanding the structure and potential orientation of water around triglycine in solution in Figures $\mathrm{C}, \mathrm{D}$ and $\mathrm{E}$ below. The radial distribution function, $G(r)_{A-B}$ indicates the density of an atom, $B$, a given distance , $r$, from a reference atom, $A$ relative to its bulk density within a system; this is proportional to the probability of finding atom $B$ at the distance $r$ from atom $A$.

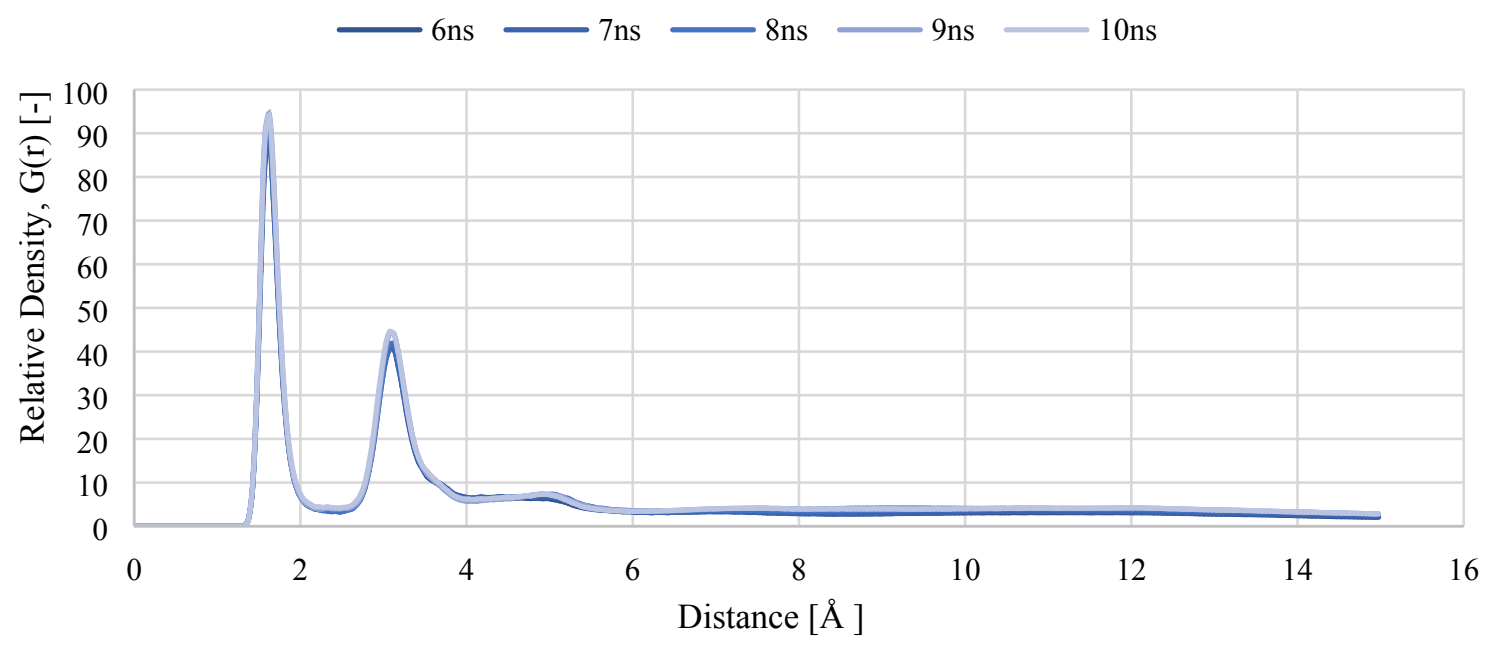

Figure S6. Radial distribution functions for the hydrogen the ammonium triglycine terminal $\left(\mathrm{NH}_{3}{ }^{+}\right)$and oxygen atoms of the carboxylate triglycine terminal (COO). Data is segmented into $1 \mathrm{~ns}$ sample sizes (e.g. $10 \mathrm{~ns}=9.0$ to $10.0 \mathrm{~ns}$ 


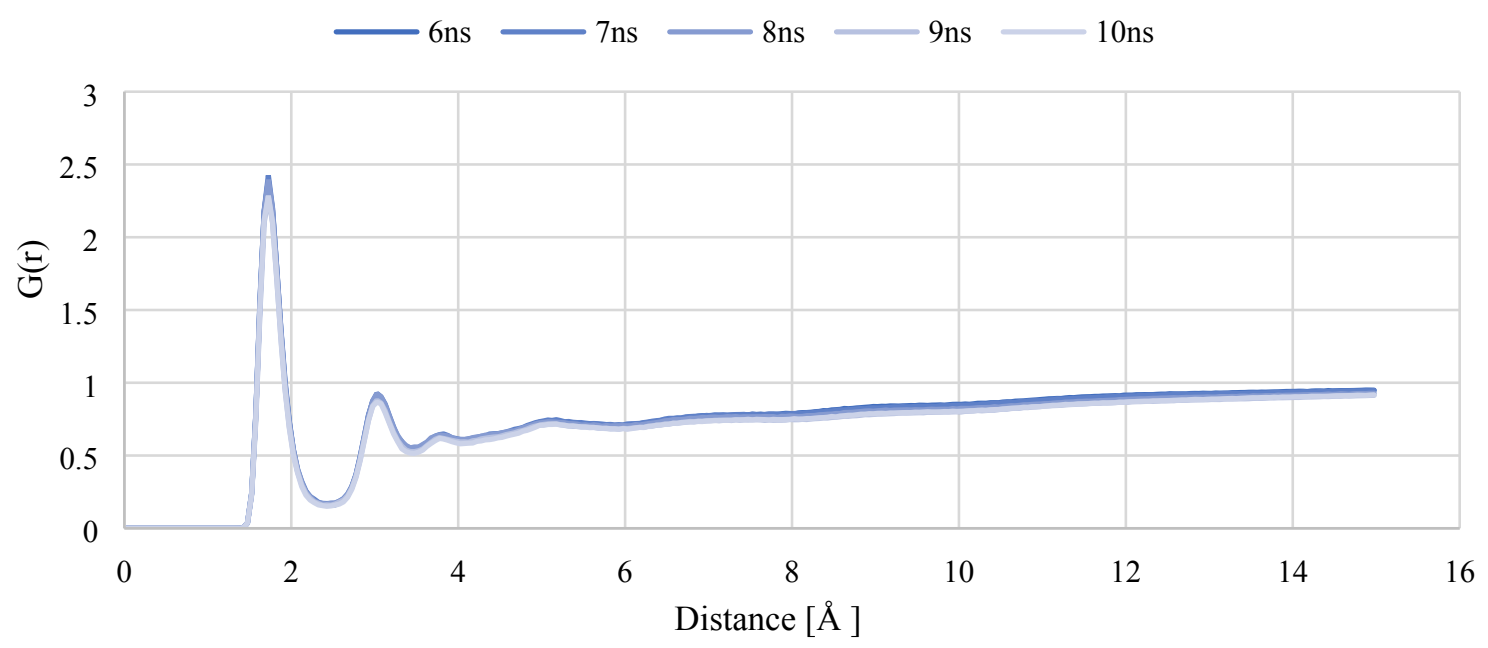

Figure S7. Radial distribution functions for the oxygen atoms of the carboxylate triglycine terminal (COO-) and the hydrogen atom of water. Data is segmented into $1 \mathrm{~ns}$ sample sizes (e.g. $10 \mathrm{~ns}=9.0$ to $10.0 \mathrm{~ns}$ ).

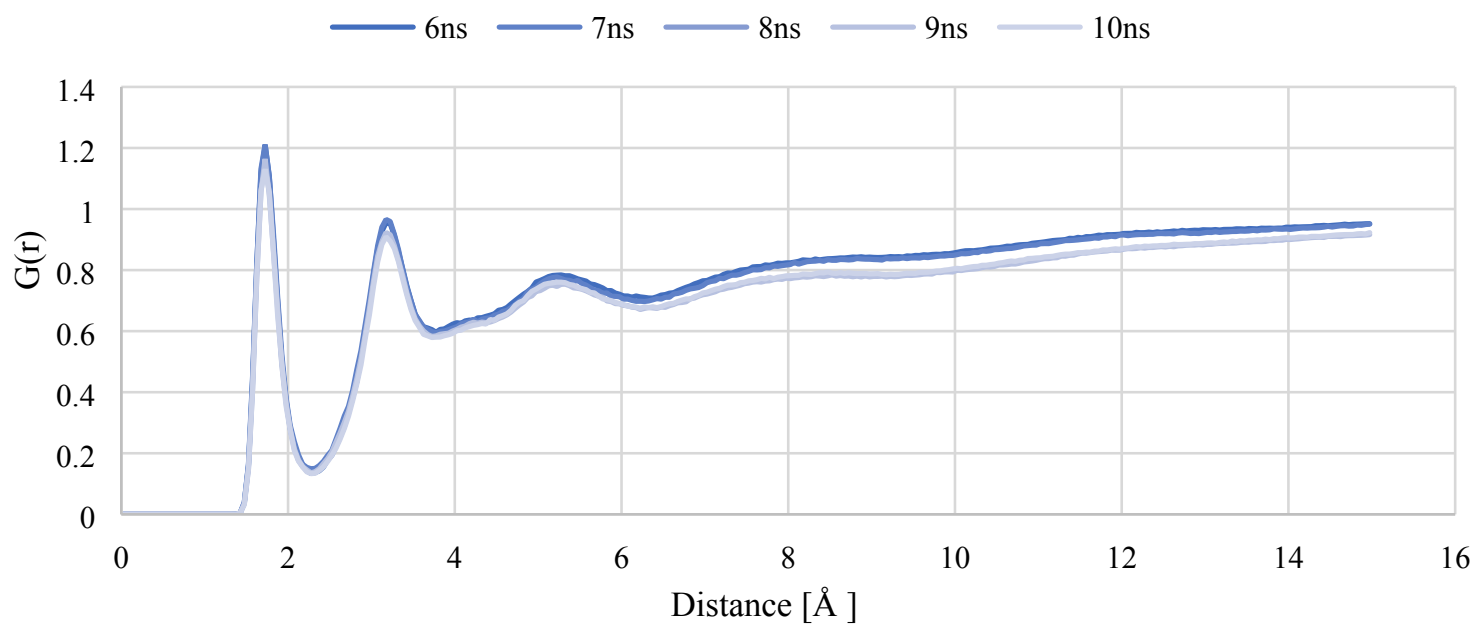

Figure S8. Radial distribution functions for the hydrogen atoms of the ammonium triglycine terminal $\left(\mathrm{NH}_{3}^{+}\right)$and oxygen atoms of water. Data is segmented into $1 \mathrm{~ns}$ sample sizes (e.g. $10 \mathrm{~ns}=9.0$ to $10.0 \mathrm{~ns}$ ).

\section{S9: Visualization of water structuring in solution via radial density functions}

A summary of the average, standard deviation and mean squared error of interactions counted between triglycine terminals and water are shown as a function of time in Table S5, S6 and S7.

Table S5: Average count of hydrogen bond interactions observed for ammonium-carboxylate functionalities in the simulated aqueous environment. Averages are taken over a $4 \mathrm{~ns}$ time interval. $\mathrm{H}$-bonds are defined as within $2.0 \AA$ and a donor acceptor angle of at least $120^{\circ}$

\begin{tabular}{cccc}
\hline Time $[\mathrm{ns}]$ & Average & Standard Deviation & Mean Squared Error \\
\hline $2-4$ & 0.932 & 9.860 & 0.029 \\
$4-6$ & 1.160 & 5.577 & 0.009 \\
$6-8$ & 1.273 & 3.366 & 0.003 \\
$8-10$ & 1.339 & 2.326 & 0.002 \\
\hline
\end{tabular}


Table S6: Average count of hydrogen bond interactions observed for water-carboxylate, functionalities in the simulated aqueous environment. Averages are taken over a 4ns time interval. $\mathrm{H}$-bonds are defined as within $2.0 \AA$ and a donor acceptor angle of at least $120^{\circ}$

\begin{tabular}{cccc}
\hline Time $[\mathrm{ns}]$ & Average & Standard Deviation & Mean Squared Error \\
\hline $2-4$ & 4.060 & 8.307 & 0.021 \\
$4-6$ & 3.667 & 9.543 & 0.027 \\
$6-8$ & 3.573 & 7.399 & 0.016 \\
$8-10$ & 3.411 & 6.093 & 0.011
\end{tabular}

Table S7: Average count of hydrogen bond interactions observed for water-ammonium functionalities in the simulated aqueous environment. Averages are taken over a 4ns time interval. $\mathrm{H}$-bonds are defined as within $2.0 \AA$ and a donor acceptor angle of at least $120^{\circ}$

\begin{tabular}{cccc}
\hline Time $[\mathrm{ns}]$ & Average & Standard Deviation & Mean Squared Error \\
\hline $2-4$ & 1.696 & 5.648 & 0.009 \\
$4-6$ & 1.428 & 5.491 & 0.009 \\
$6-8$ & 1.392 & 4.322 & 0.006 \\
$8-10$ & 1.305 & 3.911 & 0.005 \\
\hline
\end{tabular}

S10: The conformation (dihedral angle) and packing coefficient of glycine, diglycine, triglycine and TGDH<smiles>NCC(=O)[O-]</smiles>

Glycine<smiles>NCC(=O)NCC(=O)[O-]</smiles>

Diglycine<smiles>CC(CNC(=O)CNC(=O)[O-])NCC(=O)[O-]</smiles>

Triglycine

Scheme S1. The structure of glycine homopeptides with atom numbering

Table S8. The torsion of backbone and packing coefficient of Glycine homopeptides and TGDH*

\begin{tabular}{cccccc}
\hline & \multicolumn{5}{c}{ Dihedral Angles $\left(^{\circ}\right)$} \\
Peptides & $(1,2,3,4) \psi$ & $(3,4,5,6) \phi$ & $(4,5,6,7) \psi$ & $(6,7,8,9) \phi$ & Packing coefficient \\
\hline Alpha Glycine & - & - & - & - & 0.78 \\
Alpha Diglycine & 152.33 & 154.61 & - & - & 0.74 \\
Triglycine moleA & -149.88 & 177.63 & -171.50 & 172.84 & 0.76 \\
Triglycine moleB & -161.83 & -165.91 & 174.50 & 172.79 & 0.76 \\
TGDH & 177.30 & 79.85 & -138.46 & -62.54 & 0.73 \\
\hline
\end{tabular}

* Dihedral angles named using the atom numbering in Scheme S1.

Table S9. The comparison of dihedral angle of Gly(2) in triglycine dihydrate and other main secondary structures

\begin{tabular}{cccccccc}
\hline & $\alpha$-helix & $3_{10}$-helix & $\begin{array}{c}\text { Pi- } \\
\text { helix }\end{array}$ & $\begin{array}{c}\text { Parallel beta } \\
\text { sheet }\end{array}$ & $\begin{array}{c}\text { Anti- parallel } \\
\text { beta sheet }\end{array}$ & $\begin{array}{c}\text { Left-handed } \\
\text { pPII helix }\end{array}$ & $\begin{array}{c}\text { Triglycine dihydrate } \\
\text { Gly(2) }\end{array}$ \\
\hline Frequenc & Abundan & Infrequen & Rare & Abundant & Abundant & Infrequent & In this work \\
$\mathrm{y}$ & $\mathrm{t}$ & $\mathrm{t}$ & & & & & \\
$\phi$ & -57 & -49 & -57 & -119 & -139 & -75 & 79.85 \\
$\psi$ & -47 & -26 & -70 & 113 & 135 & 145 & -138.46 \\
\hline
\end{tabular}


* Glycine has a symmetric $C \alpha$, so the dihedral angle $(\phi, \psi)$ is equal to $(-\phi,-\psi)$. The second glycine residue Gly $(2)$ in the structure adopted similar dihedral angle with left-handed pPII helix.

\section{References}

(1) Dolomanov, O. V.;Bourhis, L. J.;Gildea, R. J.;Howard, J. A. K.; Puschmann, H. OLEX2: a complete structure solution, refinement and analysis program. J. Appl. Crystallogr. 2009, 42 (2), 339-341.

(2) Todorov, I. T.;Smith, W.;Trachenko, K.; Dove, M. T. DL_POLY_3: new dimensions in molecular dynamics simulations via massive parallelism. J. Mater. Chem. 2006, 16 (20), 1911-1918

(3) Galek, P. T.;Fabian, L.;Motherwell, W. D.;Allen, F. H.; Feeder, N. Knowledge-based model of hydrogenbonding propensity in organic crystals. Acta Crystallogr. B 2007, 63 (Pt 5), 768-782.

(4) Bush, I. J.;Todorov, I. T.; Smith, W. A DAFT DL_POLY distributed memory adaptation of the Smoothed Particle Mesh Ewald method. Comput. Phys. Commun. 2006, 175(5), 323-329.

(5) Yong, C. W. Descriptions and Implementations of DL_F Notation: A Natural Chemical Expression System of Atom Types for Molecular Simulations. J. Chem. Inf. Model. 2016, 56 (8), 1405-1409.

(6) Robertson M. J.; Tirado-Rives J.; Jorgensen, W.L. Improved peptide and protein torsional energetics with the OPLS-AA force field. J. Chem. Theory Comput. 2015, 11, 3499-3509.

(7) Besler, B. H. Atomic Charges Derived from Semiempirical Methods. J. Comput. Chem. 1989, 11(4), 431-439.

(8) Becke, A. D. Density-functional thermochemistry. III. The role of exact exchange. J. Chem. Phys. 1993, 98 (7), 5648-5652.

(9) Lee, C.;Yang, W.; Parr, R. G. Development of the Colle-Salvetti correlation-energy formula into a functional of the electron density. Phys. Rev. B Condens. Matter 1988, 37 (2), 785-789.

(10) Posch, H. A.;Hoover, W. G.; Vesely, F. J. Canonical dynamics of the Nose oscillator: Stability, order, and chaos. Phys. Rev. A Gen. Phys. 1986, 33 (6), 4253-4265.

(11) Hoover, W. G.; Holian, B. L. Kinetic moments method for the canonical ensemble distribution. Phys. Lett. A 1996, 211, 253-257.

(12) Yong, C. W.; Todorov, I. T. DL_ANALYSER Notation for Atomic Interactions (DANAI): A Natural Annotation System for Molecular Interactions, Using Ethanoic Acid Liquid as a Test Case. Molecules 2017, 23 (1), 36-50.

(13) Rosbottom, I.;Yong, C. W.;Geatches, D. L.;Hammond, R. B.;Todorov, I. T.; Roberts, K. J. The integrated DL_POLY/DL_FIELD/DL_ANALYSER software platform for molecular dynamics simulations for exploration of the synthonic interactions in saturated benzoic acid/hexane solutions. Mol. Simul. 2019, 1-16. 